\title{
Approach to Masses in Head and Neck Spaces
}

\author{
Ashley H. Aiken and Deborah R. Shatzkes
}

\section{Learning Objectives}

- To understand how the layers of the deep cervical fascia, along with muscles and bones, help to define compartments or "spaces" in the neck.

- To understand the normal anatomy and contents of each of these spaces in the suprahyoid and infrahyoid neck.

- To accurately localize neck pathology into a specific space in order to generate the best differential diagnosis.

\subsection{Introduction to Head and Neck Spaces}

The neck is anatomically complex but can be organized into specific "spaces" or compartments based on fascial planes and individual space contents $[1,2]$. Some authors argue that the use of the term "space" may be an oversimplification and lead to confusion. These authors propose naming fascial layers in functional terms and using the term "compartment" which can be bound by bone, muscle, and/or fascia. For the purposes of clarity and consistency with radiologic literature, this review will continue to use the term "space" but will point out potentially confusing terms and proposed newer terminology to promote interdisciplinary communication. The ability to place pathology within a neck space is the first step to generating a differential diagnosis; then specific imaging features and clinical context can be applied to narrow these different considerations.

\footnotetext{
A. H. Aiken ( ()

Department of Radiology and Imaging Sciences, Emory University

School of Medicine, Atlanta, GA, USA

e-mail: Ashley.aiken@emoryhealthcare.org

D. R. Shatzkes

Department of Radiology, Zucker School of Medicine at Hofstra/

Northwell, New York, NY, USA

e-mail: Dshatzkes@northwell.edu
}

The neck can be divided into suprahyoid and infrahyoid spaces by the hyoid bone. Some head and neck spaces transgress both the suprahyoid and infrahyoid neck. Two layers of fascia, superficial and deep, are commonly used to define the spaces of the neck. The superficial cervical fascia (SCF) is a thin layer, investing loose connective and adipose tissue, platysma, superficial lymph nodes, and muscles of facial expression. For clarification, some surgeons prefer to refer to SCF simply as "subcutaneous tissue" [3] to prevent confusion with the superficial layer of the deep cervical fascia (SLDCF), which is described below.

The deep cervical fascia is subdivided into superficial, middle, and deep layers. The superficial layer of deep cervical fascia (SLDCF) lies between the SCF (or subcutaneous tissue) and the muscles of the neck, attaching anteriorly to the hyoid, superiorly to the mandible, mastoid process, and external occipital protuberance. The "rule of twos" may be helpful to remember that the SLDCF encloses two glands (submandibular and parotid) and two muscles (sternocleidomastoid and trapezius). Some surgeons prefer to refer to subdivisions of the SLDCF as the masticator fascia, submandibular fascia, and sternocleidomastoid/trapezius fascia. In other words, in some cases, it may be helpful to define fascia by function.

The middle layer of deep cervical fascia (MLDCF) extends from the skull base to the mediastinum, and is divided into a muscular layer investing the strap muscles, and visceral layer (also called buccopharyngeal in the suprahyoid neck) investing the larynx, pharynx, trachea, esophagus, and thyroid. The deep layer of deep cervical fascia (DLDCF) surrounds the vertebral column and paravertebral muscles with two distinct components: the alar and prevertebral fascia. The alar layer forms the posterior and lateral walls of the retropharyngeal space and bridges the transverse processes of the vertebrae. The prevertebral layer encloses the paraspinal muscles: the longus colli and longus capitis muscles; the anterior, middle, and posterior scalene muscles; and the levator scapulae. The carotid sheath is generally thought to be composed of all three layers of DCF; however, the thick- 
ness of the carotid sheath varies between individuals and at different levels in the neck.

The suprahyoid neck spaces comprise the area from the base of skull to the hyoid bone, excluding the orbits, paranasal sinuses, and oral cavity. The spaces of the suprahyoid neck include the pharyngeal mucosal space (PMS), the sublingual space (SLS), the submandibular space (SMS), the parapharyngeal space (PPS), the parotid space (PS), and masticator space (MS). The entire neck (suprahyoid plus infrahyoid) spaces include the carotid space (CS), retropharyngeal and danger space (RPS), and the perivertebral space (PVS). In addition to the entire neck spaces (above), infrahyoid neck contains the visceral space (VS), which comprises the thyroid and parathyroid glands and the larynx, hypopharynx, trachea, and cervical esophagus.

\subsection{Suprahyoid Neck: Pharyngeal Mucosal Space (PMS)}

Anatomy and Contents Contents of the pharyngeal mucosal space include the mucosa of the nasopharynx and oropharynx, as well as submucosal structures such as Waldeyer's ring, minor salivary glands (MSGs), the pharyngeal constrictor and levator veli palatine muscles, and the torus tubarius bordering the Eustachian tube orifice [4]. Waldeyer's ring comprises the adenoids and the palatine and lingual tonsils; the ring-like configuration of lymphoid tissue can be thought of as a mechanism of protecting the body from inhaled and ingested antigens. Deep mucosa-lined tonsillar crypts result in a characteristic striped appearance on contrast-enhanced imaging and may hide small primary tumors.

\section{Key Point}

- While squamous cell carcinoma is the most common tumor of the PMS, the presence of Waldeyer's ring lymphoid tissue and submucosal minor salivary glands may result in lymphoproliferative and salivary neoplasms, respectively.

Pathology Squamous cell carcinoma arising from the mucosa represents the most common malignant neoplasm in this space and is covered in a separate chapter. Tumors arising from Waldeyer's ring lymphoid tissue and MSGs are considerably less common. Inflammatory disease of the oropharynx represents a spectrum ranging from non-focal tonsillitis to tonsillar or peritonsillar abscess. (Fig. 16.1) Congenital lesions of the PMS include the central nasopharyngeal Tornwaldt cyst and those related to the embryologic thyroglossal duct, including cysts and the lingual thyroid. (Fig. 16.2).

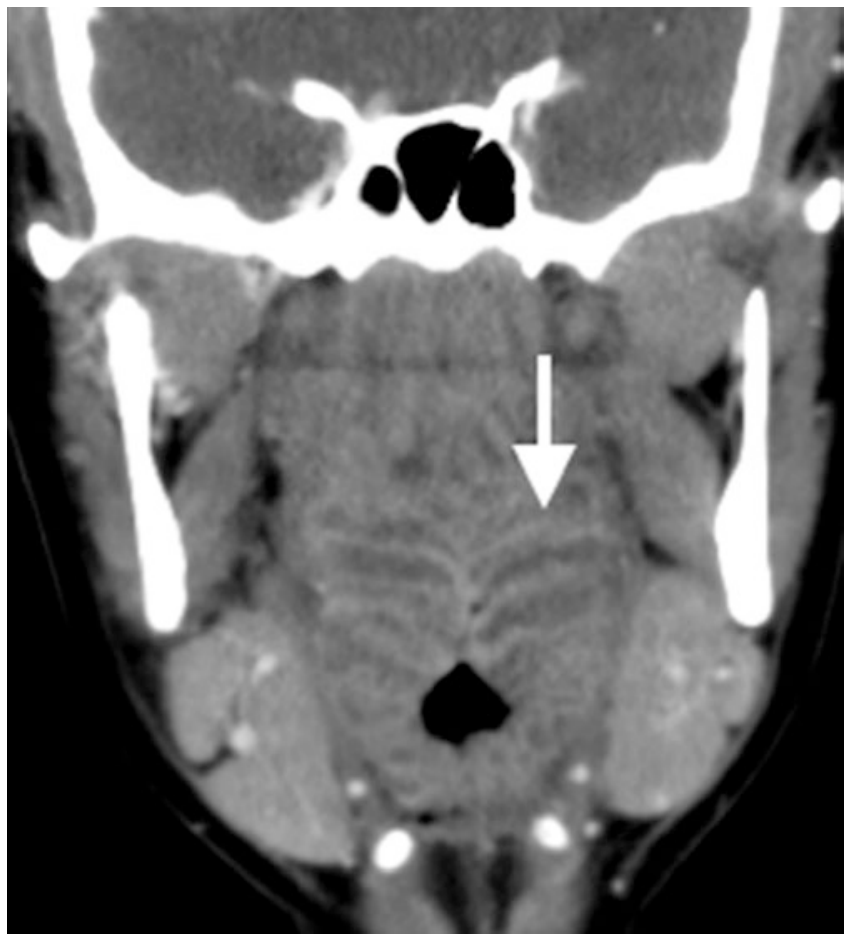

Fig. 16.1 CECT shows characteristic striped appearance of the inflamed mucosa of Waldeyer's ring in a patient with tonsillitis and adenoiditis

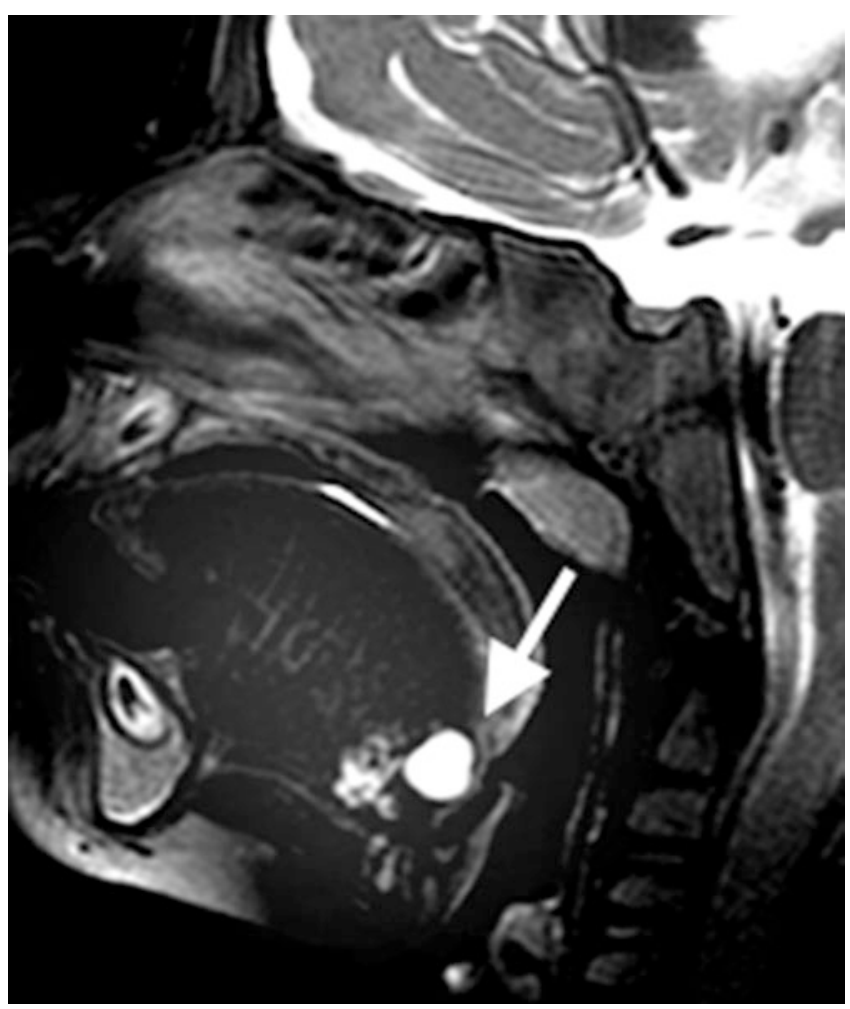

Fig. 16.2 Sagittal T2WI demonstrates a thyroglossal duct cyst at the base of tongue, part of the oropharynx. Adenoidal tissue lines the nasopharyngeal roof 


\subsection{Suprahyoid Neck: Parapharyngeal Space (PPS)}

Anatomy and Contents The PPS represents a triangular fatcontaining space lateral to the PMS, bounded laterally by the masticator and parotid spaces, posteriorly by the retropharyngeal and carotid spaces, and superiorly by the skull base, with inferior extension into the submandibular space. The PPS contents are simple: fat, minor salivary glands, and, rarely, lymph nodes.

Pathology Pathology primary to the PPS is rare, with the majority of lesions salivary in origin and representing benign mixed tumors (BMTs) [5]. The PPS is primarily impacted by pathology of neighboring spaces, and the pattern of deviation or deformity of the PPS fat may be helpful in identifying the space of origin. For example, while a well-defined markedly T2-hyperintense mass bounded entirely by fat is likely a primary PPS BMT, a similar lesion contiguous with the deep lobe of the parotid and displacing the PPS fat anteromedially more likely originates in the parotid space (Fig. 16.3). Similarly, masticator space lesions displace the PPS fat posteromedially, PMS lesions laterally, and carotid space lesions anteriorly.

\subsection{Suprahyoid Neck: Masticator Space (MS)}

Anatomy and Contents The MS is located lateral to the PPS, and contains the muscles of mastication (masseter, temporalis, medial and lateral pterygoids), posterior body and ramus of the mandible and the mandibular nerve, a branch of the trigeminal nerve.
Pathology As with the PPS, most pathology of the MS arises in the neighboring spaces, with the most common being odontogenic infection arising from molar teeth within the neighboring oral cavity [6]. Dental abscesses may extend to the medial pterygoid or masseter muscles and may also result in osteomyelitis of the posterior mandibular body and condyle (Fig. 16.4). Another common non-neoplastic lesion affecting the MS is the venous malformation (VM), which has a predilection for the muscles of mastication and is a frequent incidental finding on

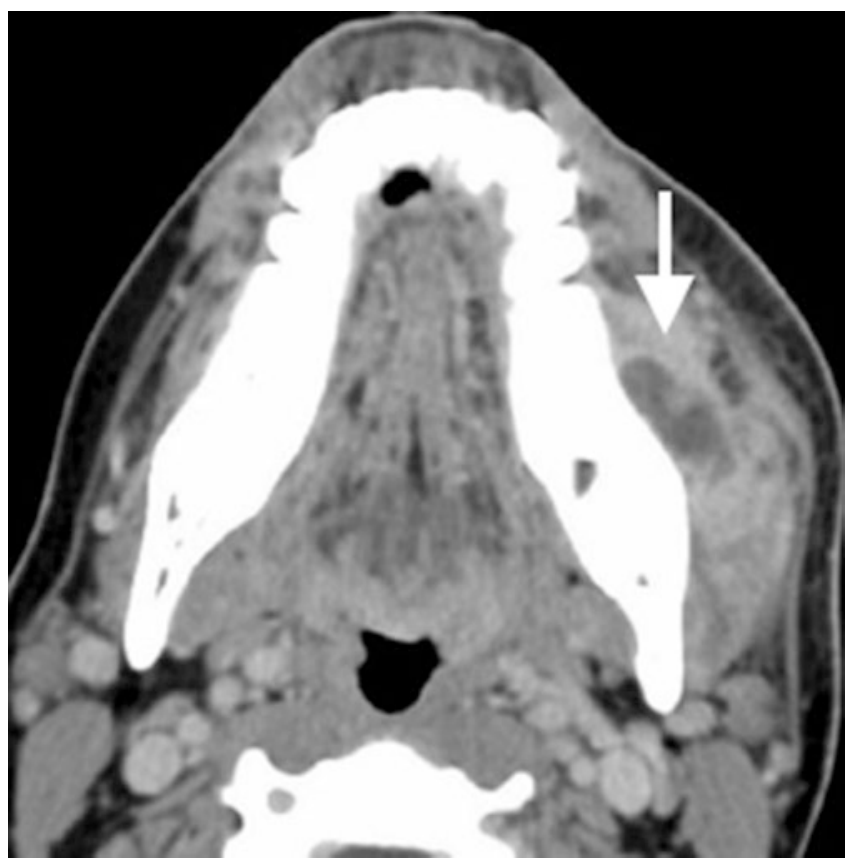

Fig. 16.4 Axial CECT image shows a fluid collection within the enlarged left masseter muscle, representing an odontogenic abscess arising from the left mandibular third molar tooth
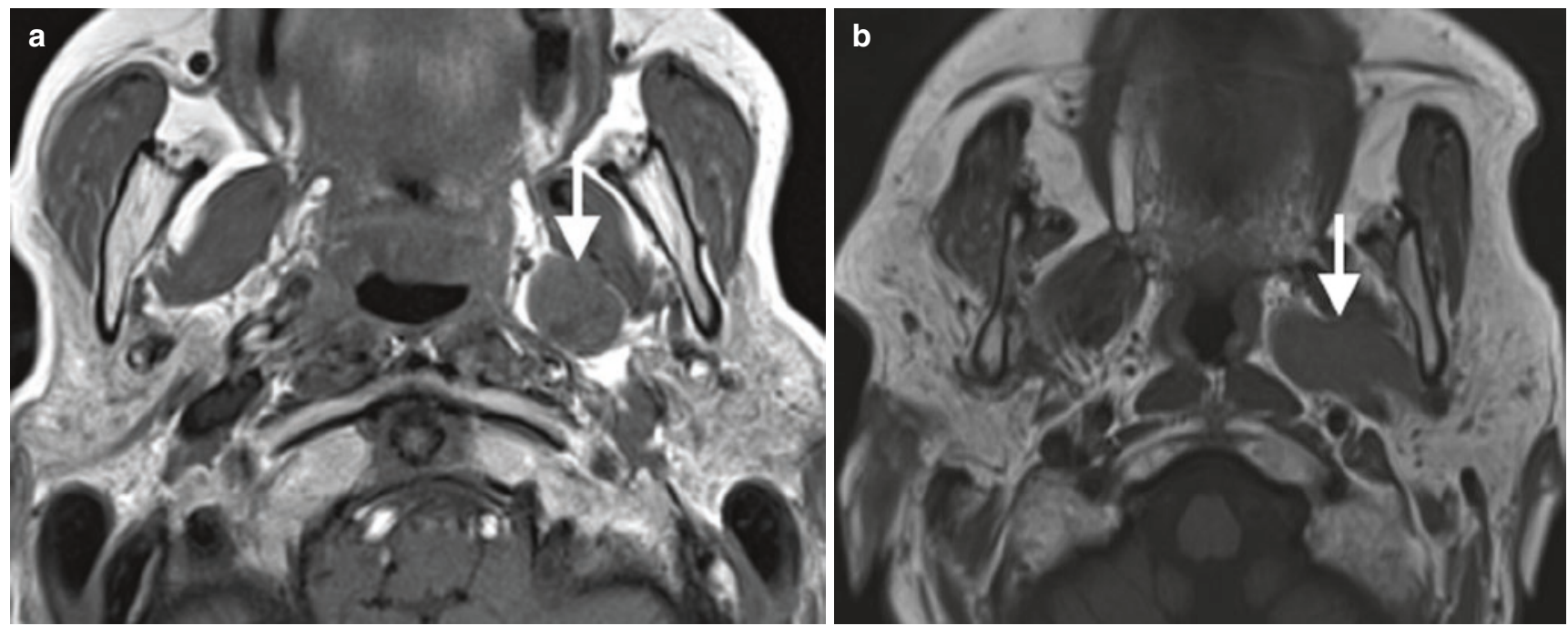

Fig. 16.3 (a) Primary BMT of the left PPS is surrounded entirely by fat on axial T1-weighted image. (b) Axial T1-weighted image shows a primary BMT of the left parotid space inseparable from the deep lobe and displacing PPS fat medially 
imaging studies performed for unrelated indications (Fig. 16.5) The presence of phleboliths within a heterogeneously enhancing and markedly T2-hyperintense mass is virtually pathognomonic for VM. Cranial nerve V3 may be involved secondarily by perineural spread of tumor, or, much less commonly, by primary nerve sheath tumors such as schwannomas. Primary neoplasms of the muscles of mastication, such as sarcomas and

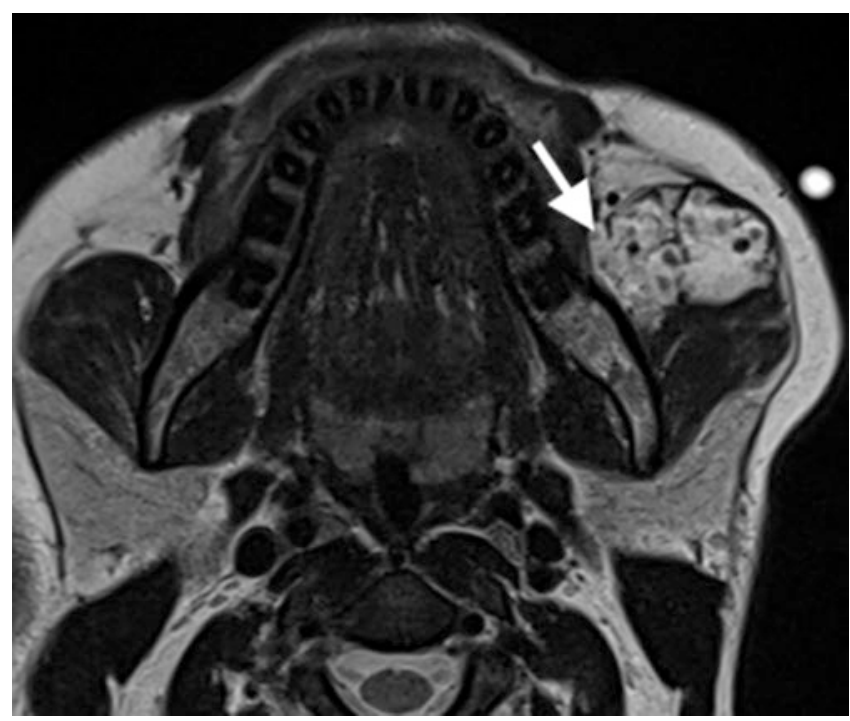

Fig. 16.5 Axial T2-weighted image shows a markedly hyperintense mass in the anterior left masseter muscle with internal round areas of signal void. These represent phleboliths and are virtually pathognomonic for a venous malformation

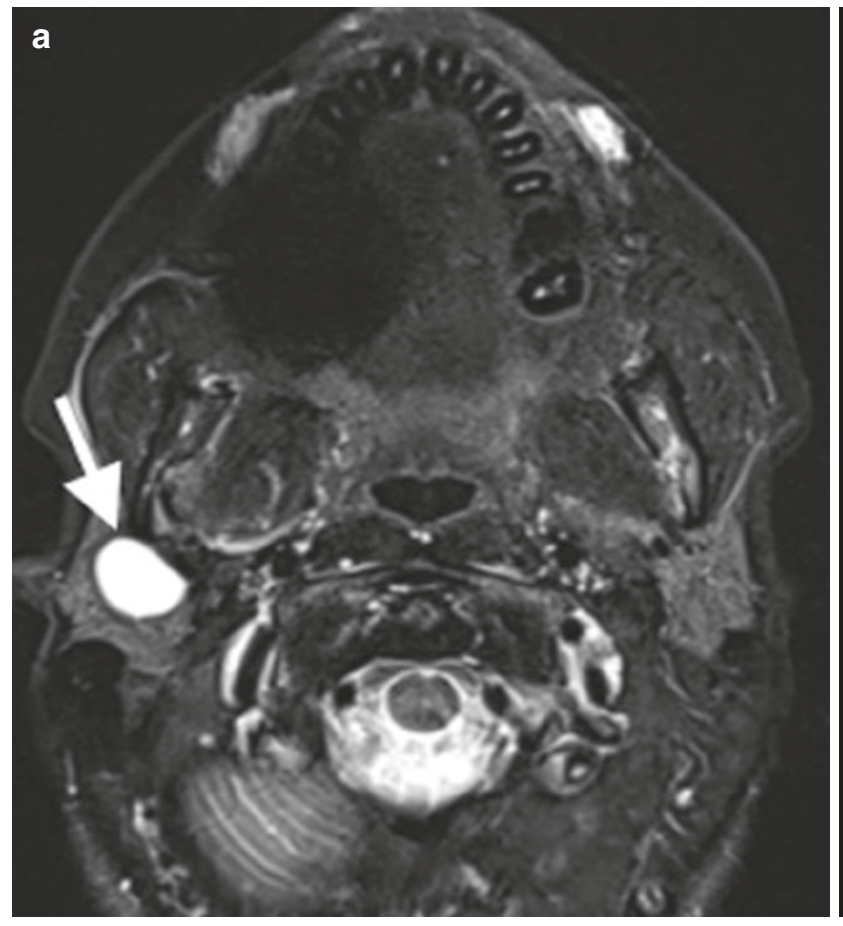

Fig. 16.6 (a) Axial STIR image demonstrates marked T2 prolongation of a well-defined mass in the right parotid superficial lobe found to represent a benign mixed tumor. (b) Corresponding ADC image dem- lymphoproliferative malignancies, are exceedingly rare. More often, malignant MS disease results from spread of tumors arising in the pharynx, oral cavity, or parotid space.

\subsection{Suprahyoid Neck: Parotid Space (PS)}

Anatomy and Contents The PS contains the parotid gland, facial nerve, retromandibular vein, and branches of the external carotid artery. The plane of the facial nerve bisects the gland into superficial and deep lobes; localization of lesions into these lobes is important in the prevention of inadvertent facial nerve injury during resection. This plane may be approximated on cross-sectional imaging by identifying the stylomandibular tunnel, between the styloid process and the posterior cortex of the mandibular condyle, as well as by the position of the retromandibular vein.

Pathology The parotid gland is the only salivary gland to contain lymph nodes, with the important consequence that the differential diagnosis for lymphadenopathy, including neoplastic and inflammatory etiologies, must be considered for any PS mass [7]. The parotid lymph nodes also represent first echelon drainage for cancers of the external auditory canal as well skin cancers of portions of the scalp and facial skin. Fortunately, most primary salivary epithelial neoplasms represent the benign mixed tumor (pleomorphic adenoma), which demonstrates very high signal on T2-weighted and ADC scans (Fig. 16.6). This is one of the few parotid neoplasms that dem-

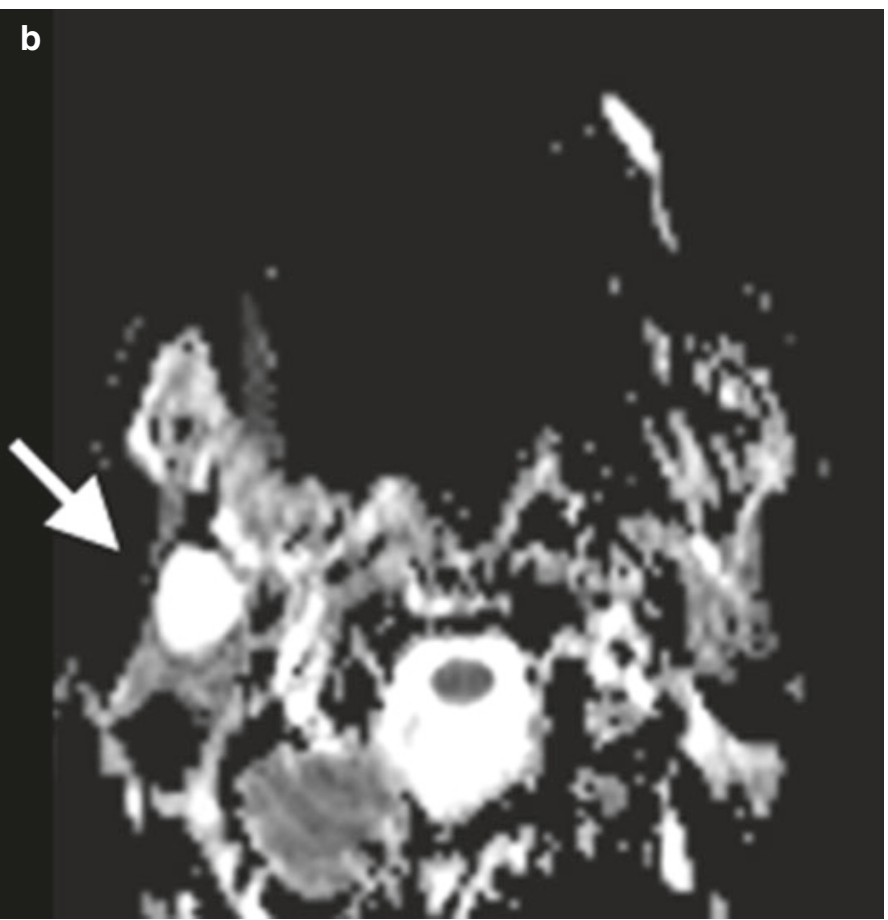

onstrates high signal reflecting the gelatinous nature of these tumors with relative free diffusivity of water 
onstrate characteristic imaging features; in general, given the very diverse neoplastic histology of this region, a specific diagnosis cannot be reliably predicted based on CT or MR imaging. Acute parotitis may occur secondary to obstruction by calculi, retrograde migration of oral flora secondary to poor salivary flow, or hematogenic viral infection. Chronic parotitis is typically bilateral and reflects underlying systemic disease such as Sjogren syndrome or sarcoidosis.

\section{Key Point}

- The parotid gland is the only salivary gland to contain lymph nodes; the differential diagnosis for lymphadenopathy must be considered for any PS mass.

\subsection{Suprahyoid Neck: Sublingual (SLS) and Submandibular Space (SMS)}

Anatomy and Contents The oral cavity is an anatomically complex area with an extensive convoluted mucosal surface covering its constituent structures, including the tongue, floor of mouth, hard palate, cheeks, and gingiva. The SLS is the portion of the floor of mouth below the tongue and above the mylohyoid muscle, a sling-like structure that separates the OC above from the SMS below (Fig. 16.7) [8]. The SLS contains the sublingual glands (SLGs), the deep lobes of the submandibular glands (SMGs) and submandibular ducts, the "neurovascular bundles" (lingual nerves, arteries, and veins), and cranial nerves 9 and 12 . The SMS is relatively simple in composition, containing only the SMG superficial lobes, fat, lymph nodes, and the facial artery and vein.

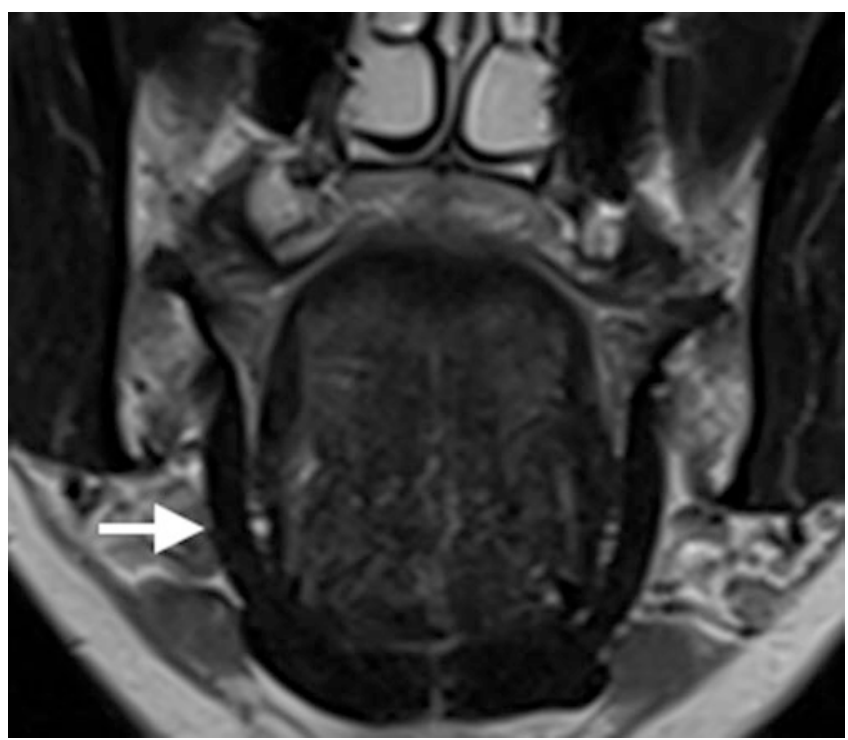

Fig. 16.7 Coronal T2 weighted image shows the sling-like mylohyoid muscle that separates the oral cavity above from the SMS below

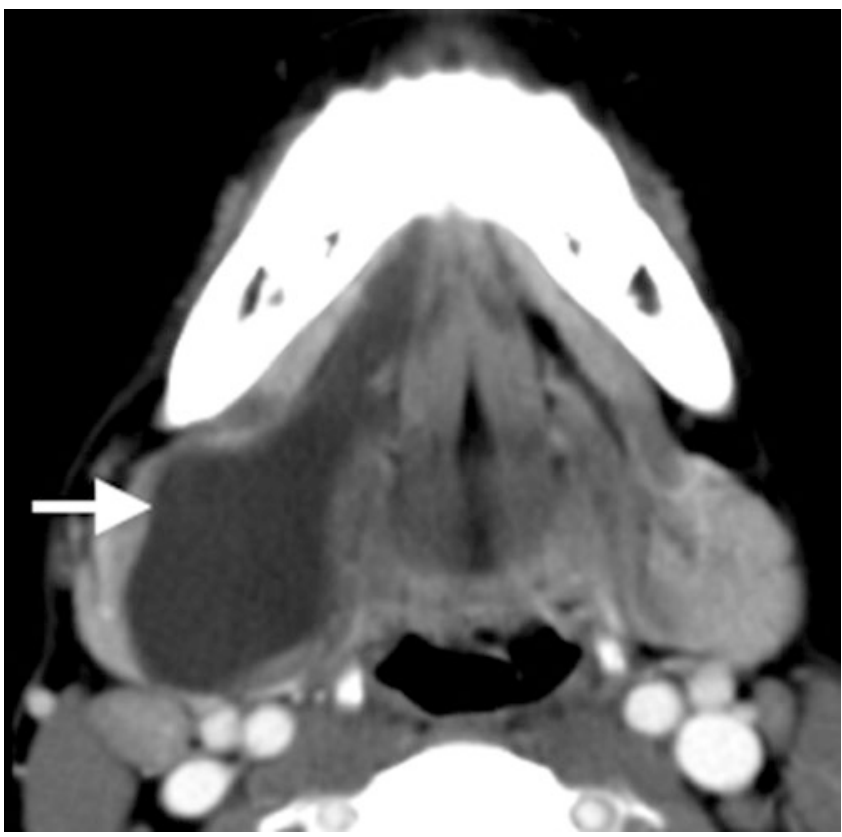

Fig. 16.8 Axial CECT depicts a "diving" or "plunging" ranula extending from the SLS to the SMS behind the posterior free edge of the mylohyoid muscle

Pathology The teeth and salivary glands are important sources of inflammatory disease in both the SLS and SMS, with the vast majority of neoplasms in this region representing squamous cell carcinoma originating from the $\mathrm{OC}$ mucosa. Salivary epithelial tumors may arise from the major salivary glands (SLG, SMG) or from minor salivary glands (MSGs) lying within the SLS submucosal space. Obstruction of the SLG or a submucosal MSG duct may result in formation of a ranula, an epithelial-lined cyst within the SLS. When these rupture, they may form pseudocysts that may "dive" or "plunge" behind the posterior free edge of the mylohyoid muscle into the SMS (Fig. 16.8).

\subsection{Infrahyoid Neck: Visceral Space (VS)}

Anatomy and Contents The VS is a central tubular space extending from the hyoid to the mediastinum, enclosed by the middle layer of deep cervical fascia. It is the only space found entirely in the infrahyoid neck. It contains the thyroid and parathyroid glands, the recurrent laryngeal nerve, the larynx, hypopharynx, trachea, and cervical esophagus. The thyroid gland is located anterior to the prevertebral musculature and posterior to the infrahyoid strap musculature, in close proximity to other structures of the visceral space including the larynx, trachea, and esophagus. The tracheoesophageal groove lies posteromedial to the thyroid lobe, and contains several important structures including the recurrent laryngeal nerve, paratracheal nodes, and parathyroid glands. 
Thyroid and Parathyroid Pathology Abnormalities of the thyroid gland are a major indication for imaging the visceral space. In general, ultrasound is the workhorse imaging modality for inflammatory (Hashimoto's) or infectious thyroiditis and for evaluation of the intrathyroidal nodule. Intrathyroidal nodules may represent colloid cysts, adenomas, differentiated thyroid cancer, or even the rare metastases. Many ultrasound classification systems exist to risk stratify these nodules and decide on biopsy, including ones by the American Thyroid association (ATA) and Society of Radiologists in Ultrasound (SRU), and also new systems such as European (EU-TIRADS) and American College of Radiology Thyroid Imaging and Reporting Data System (ACR TIRADS) are gaining acceptance for its point based approach $[9,10]$.

Thyroid cancer is a heterogeneous group of malignancies, including differentiated thyroid carcinomas (papillary and follicular), medullary and anaplastic carcinomas, and non-Hodgkin lymphoma. Cross-sectional imaging is more appropriate when there is a concern for extrathyroidal extension of tumor [11, 12] (Fig. 16.9) into surrounding structures such as the trachea or esophagus. For rapidly enlarging thyroid masses, anaplastic carcinoma and lymphoma should be considered. For multinodular goiters (MNG), ultrasound is used for surveillance of individual nodules, but non-contrast CT (NCCT) is often the choice for presurgical evaluation if airway compression necessitates removal. NCCT is helpful to evaluate the extent of airway compression, substernal extension for surgical planning and to exclude overt signs of malignancy.

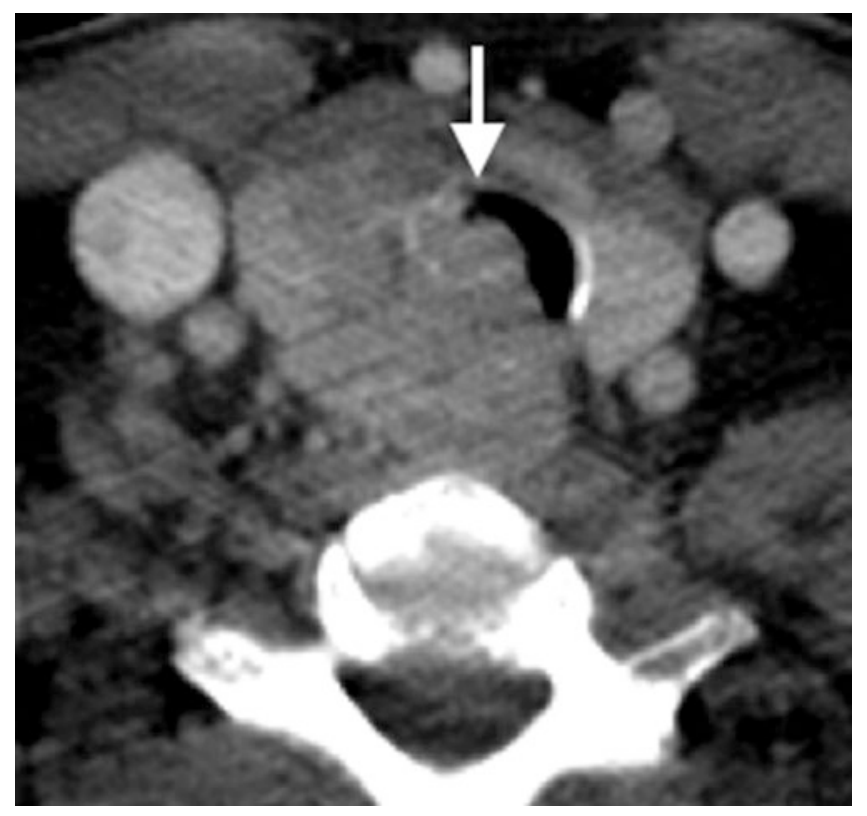

Fig. 16.9 Axial CECT shows a papillary thyroid cancer with extrathyroidal extension and invasion of the trachea (arrow) and esophagus

\section{Key Point}

- US is the primary imaging modality for both inflammatory disease and work-up of thyroid nodules, with cross-sectional imaging used when there is concern for extrathyroidal extension of tumor, or to evaluate potential airway compression or substernal extension.

Congenital lesions in the visceral space include infrahyoid thyroglossal duct cysts or ectopic thyroid tissue along the course of the thyroglossal duct. (Fig. 16.10) Thyroglossal duct cysts are the most common congenital neck masses; most present before age ten as a painless, movable mass that may fluctuate in size after upper respiratory tract infection. When suprahyoid, they are characteristically midline and when infrahyoid, they are often para-midline.

Nodules in the tracheoesophageal groove may represent parathyroid adenomas or carcinomas, lymph nodes or rarely schwannomas of the recurrent laryngeal nerve. Parathyroid adenomas are characteristically hypervascular, demonstrating rapid washin on early arterial phase and relatively rapid washout on venous phase multiphase contrast enhanced CT [13].

Larynx, Hypopharynx, Trachea, and Esophagus Pathology The larynx and hypopharynx are most commonly imaged for staging squamous cell carcinoma (a primary mucosal space abnormality), covered in a separate

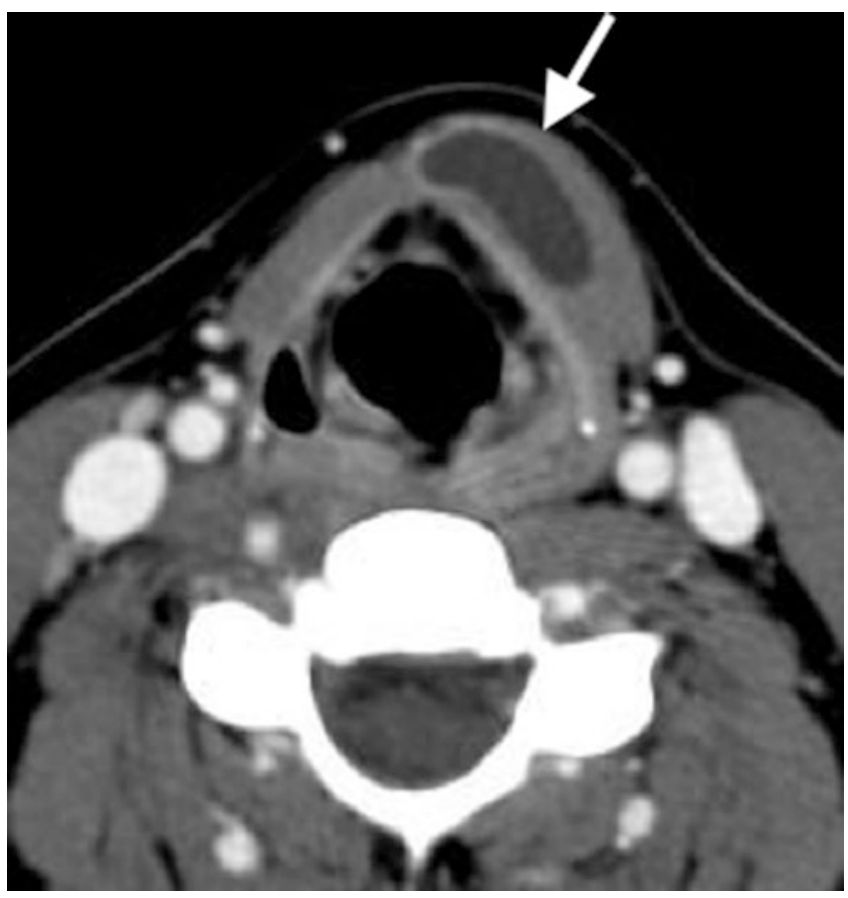

Fig. 16.10 Axial CECT shows an infrahyoid off-midline cystic lesion (arrow), embedded in the strap musculature, compatible with a thyroglossal duct cyst 


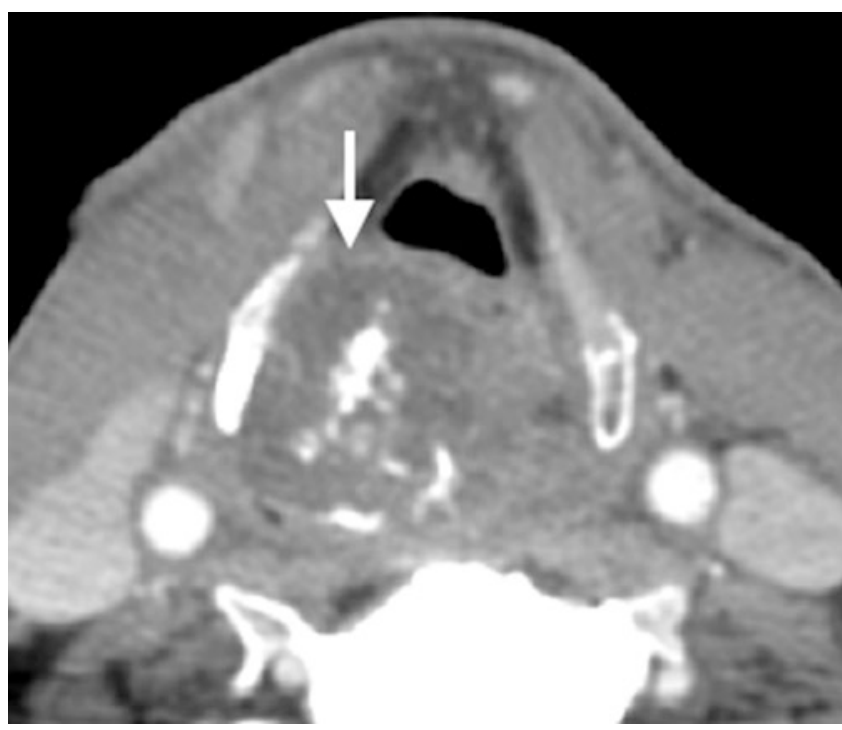

Fig. 16.11 Axial CECT shows an expansile mass replacing the right cricoid cartilage with popcorn or ring-like calcification (arrow). On endoscopy, the surgeons saw a submucosal mass. Findings are compatible with a chondrosarcoma

chapter. More rare submucosal tumors are usually well circumscribed on imaging and will not have an overlying mucosal abnormality on endoscopy. The $\mathrm{ddx}$ for submucosal masses includes minor salivary gland tumors, sarcomas, and lymphoma. Laryngeal chondrosarcomas most often arise in the cricoid cartilage with cartilage destruction, ring-like calcification, and bright T2 signal on MRI (Fig. 16.11). Benign lesions of the larynx, including papillomas and hemangiomas, are also more rare.

Epiglottitis should be suspected in a child with difficulty breathing and swallowing and may initially be evaluated with plain film. When there is a classic "thumb" sign reflecting the swollen epiglottis, treatment may be initiated and CECT may not even be required. Adults may have supraglottis with CECT showing thickened epiglottis and aryepiglottic folds.

\subsection{Entire Neck: Carotid Space}

Anatomy and Contents The carotid space spans the suprahyoid and infrahyoid neck, extending from the skull base to the aortic arch, with all three layers of the deep cervical fascia contributing to the carotid sheath [14]. It is located posterior to the styloid process (and is referred to as the post-styloid PPS by some authors), anterior to the prevertebral muscles, and lateral to the retropharyngeal space. The space can be subdivided into nasopharyngeal, oropharyngeal, cervical and mediastinal components. The suprahyoid CS contains the carotid artery, internal jugular vein (IJV), cranial nerves, IX, X, XI, XII, and the sympathetic chain. The infrahyoid CS differs in that all cranial nerves have exited except the vagus nerve. Lymph nodes are closely associated with the carotid space, along its lateral border. The carotid artery is located medially, IJV laterally, vagus nerve posteriorly along the vessels, and the sympathetic chain posteriorly within the sheath.

\section{Key Point}

- The CS spans the suprahyoid and infrahyoid neck, with all three layers of the DCF contributing to the carotid sheath.

Pathology Masses in the suprahyoid carotid space classically displace the parapharyngeal fat anteriorly and splay the carotid and jugular vein, often displacing the ICA anteriorly and IJV posterolaterally. Vascular pathology, primarily dissection or pseudoaneurysm of the carotid artery or thrombosis/thrombophlebitis of the IJV, may easily be overlooked on routine neck CT or MRI. Specific attention should be paid to the carotid space to exclude dissection in any patient presenting with Horner's syndrome (Fig. 16.12). An IJV thrombophlebitis caused by an extension of oropharyngeal or odontogenic infection is referred to as Lemierre syndrome. CT and MR angiography or venography are studies of choice if there is high clinical suspicion for a vascular lesion.

The most common masses in the high nasopharyngeal carotid space, including glomus jugular paraganglioma, schwannoma and meningioma, often dumbbell inferiorly from the jugular foramen. Close attention to the skull base is important in any patient presenting with hoarseness/ vocal cord palsy or other cranial neuropathy involving $\mathrm{CNs}$ IX-XII. Bony changes on CT are an important clue to the correct diagnosis of a jugular foramen/carotid space mass at the skull base. Permeative destruction favors paraganglioma, smooth remodeling schwannoma, and hyperostosis meningioma. On MRI, paragangliomas are intensely enhancing and can have the classic "salt and pepper" appearance with the "salt" representing microhemorrhages on T1-weighted (T1W) images and the pepper representing flow voids on T2-weighted (T2W) images. Glomus vagale and carotid body paragangliomas are also found in the carotid space. The rare vagale tumors arise along the high extracranial portion of the vagus nerve in the high nasopharyngeal carotid apace and can extend intracranially. Carotid body tumors are located at the carotid bifurcation in the infrahyoid neck and splay the internal and external carotid arteries.

Carotid space nerve sheath tumors include schwannomas and neurofibromas. CS schwannomas are benign tumors of Schwann cells that invest CNs 9-12, most commonly CN 10 (vagus). Neurofibromas are benign spindle cell neoplasms arising from the vagus nerve, hypoglossal nerve, or sympathetic chain and are associated with neurofibromatosis type 1. Schwannomas are typically fusiform enhancing tumors, 


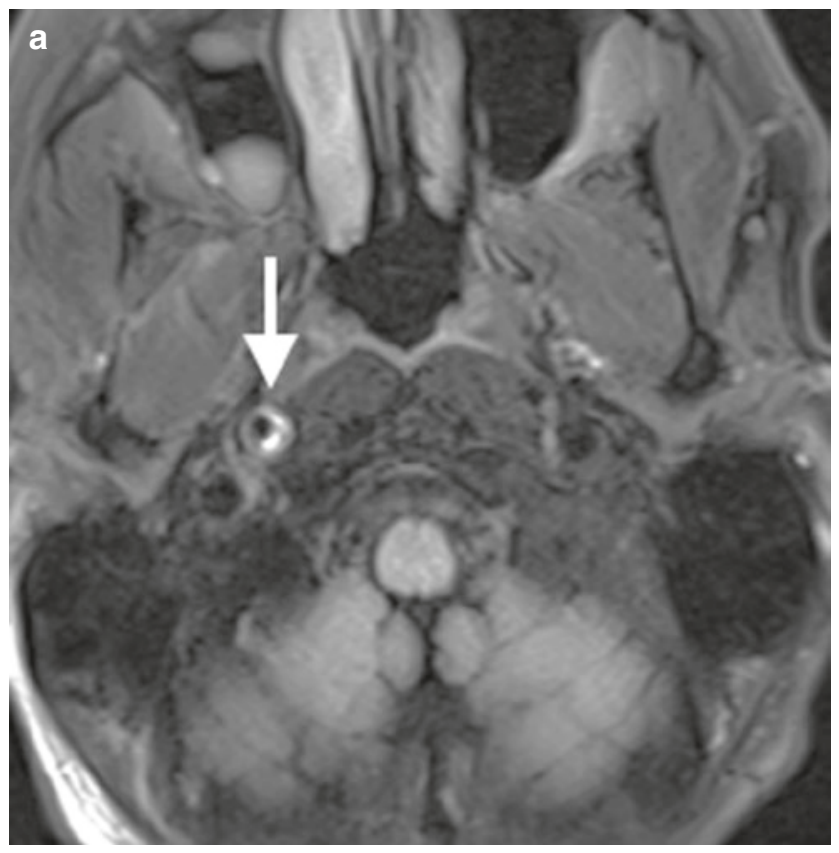

Fig. 16.12 (a) Axial flair sequence shows crescentic shaped mural hyperintensity along the medial right ICA wall (arrow), expanding the caliber of the ICA, but only minimally narrowing the lumen. (b) The source image from a 3D time of flight also shows this crescentic high

sometimes with cystic change, whereas neurofibromas are classically hypodense and hypoenhancing on CT and have a characteristic target sign on MRI. Nasopharyngeal CS schwannomas displace the PPS fat anteriorly, the styloid anterolaterally, the ICA anteromedially, and the IJV posterolaterally (Fig. 16.13). This is in contradistinction to sympathetic chain schwannomas which displace the carotid artery and jugular vein together anteriorly. Oropharyngeal CS tumors also displace the PPS fat anteriorly but also displace the posterior belly of the digastric muscle laterally. Infrahyoid neck CS nerve sheath tumors displace the carotid anteromedially.

\subsection{Entire Neck: Retropharyngeal, Prevertebral and Danger Spaces (RPS)}

Anatomy and Contents As mentioned in the introduction, the DLDCF has two components, the alar and prevertebral fascia, and this results in the formation of three posterior neck spaces: (1) retropharyngeal space (RPS), between the visceral and alar fascia, (2) danger space, between the alar and prevertebral fascia, and (3) prevertebral space, between the prevertebral fascia and the vertebral periosteum (part of the perivertebral space, discussed below). The importance of recognizing the division into these spaces primarily relates to

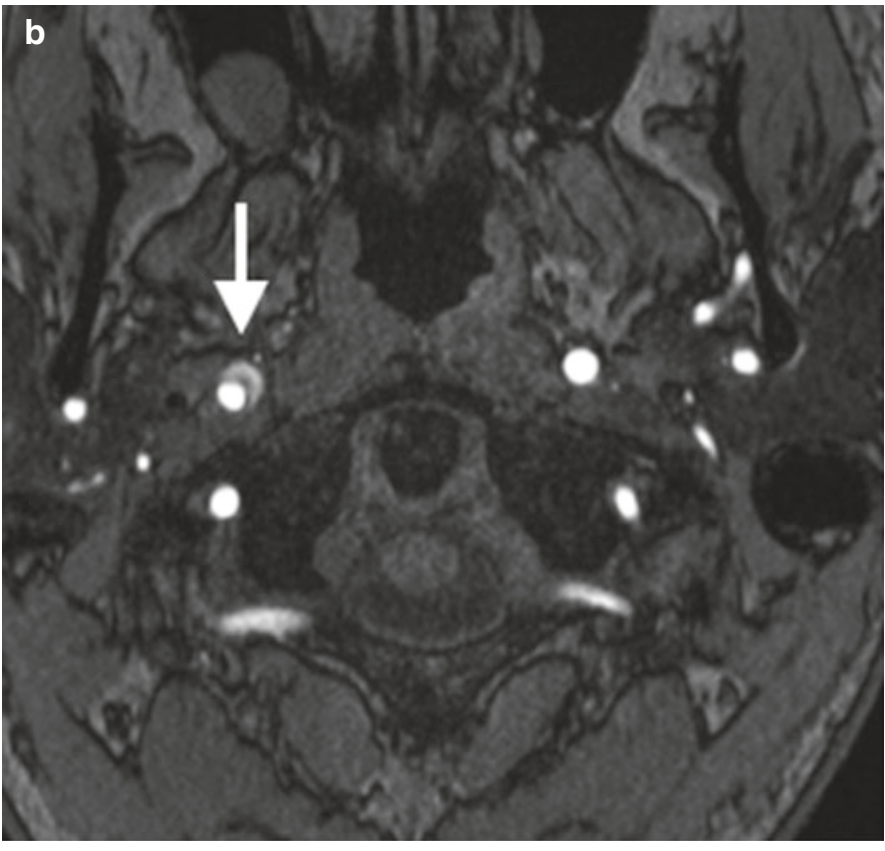

T1 signal (arrow) because of intrinsic T1 shortening, but on the MIP images from the post gadolinium MRA, a caliber change in the lumen could barely be perceived

their inferior extent. While the RPS terminates at the level of the T3 vertebra, the danger space extends more inferiorly to a point just above the diaphragm, and the prevertebral space continues to the coccyx. Though we typically cannot distinguish these spaces on imaging, we must remember to follow a posterior neck space collection to its inferior extent, recognizing that this may lie within the chest or below. Contents of the RPS are simple, consisting of fat and lymph nodes.

\section{Key Point}

- Retropharyngeal collections that have entered the danger or prevertebral spaces can descend to the mediastinum and as far inferiorly as the coccyx.

Pathology Disease processes in the RPS can be categorized as related to nodal pathology and/or the presence of fluid. Fluid within the RPS may be encapsulated and represent an abscess (Fig. 16.14) or, much less commonly, a pseudomeningocele representing a complication of spinal surgery. More frequent is edema or effusion of the RPS and this may occur as a reaction to a wide variety of disease processes, including pharyngitis, lymphatic or venous obstruction, angioedema, and radiation therapy [15]. Nodal enlargement may occur in the setting of inflammatory or neoplastic processes. When 


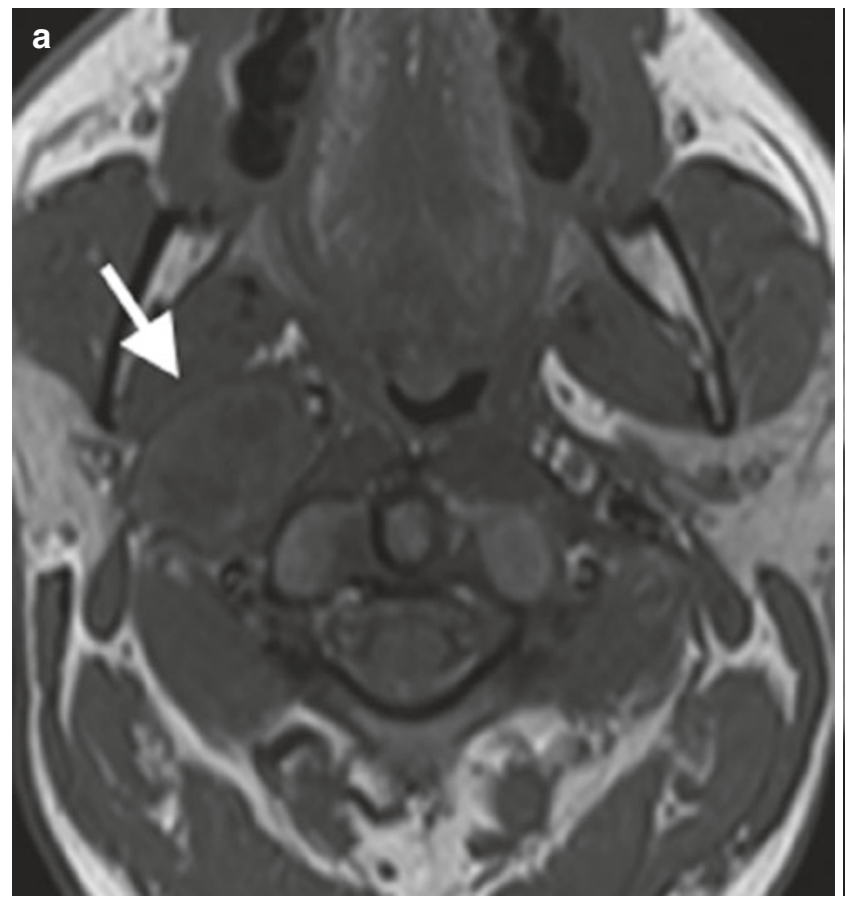

Fig. 16.13 (a) Axial T1-weighted image shows a $\mathrm{T} 1$ isointense mass which displaces the PPS fat anteriorly. This suggests that the mass originates in the carotid space. (b) Axial postgadolinium, fat saturated T1-weighted image shows a fusiform, enhancing mass with central cys-

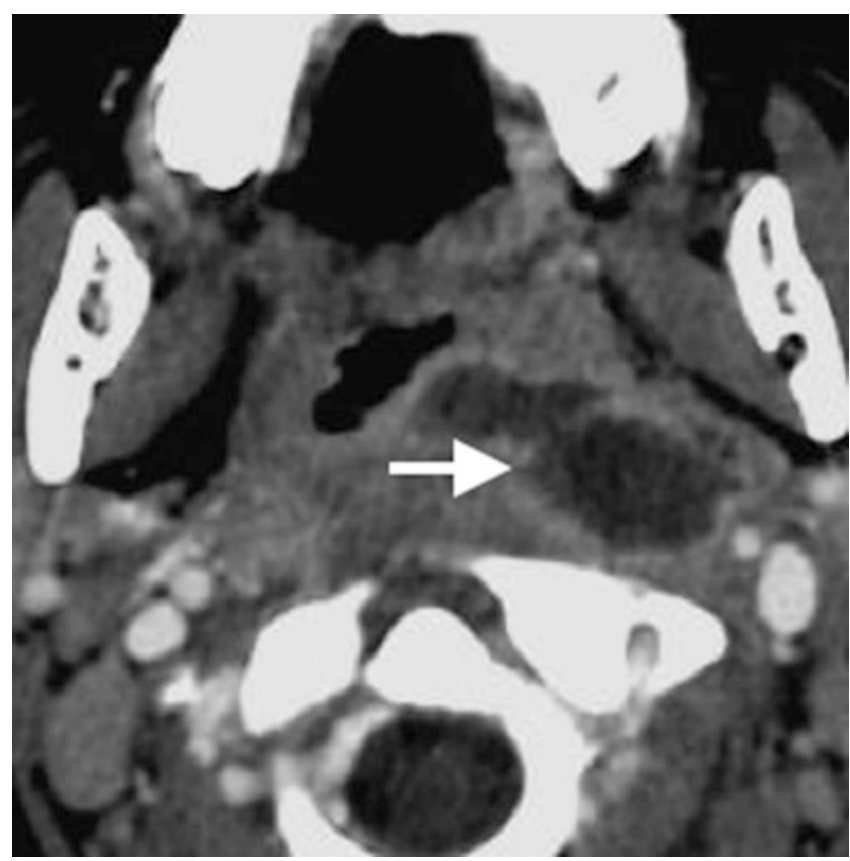

Fig. 16.14 Axial CECT image shows suppurative retropharyngeal lymphadenopathy in a child with streptococcal pharyngitis. Note that the intranodal abscess has ruptured medially and is spilling into the RPS, where it may form a retropharyngeal abscess

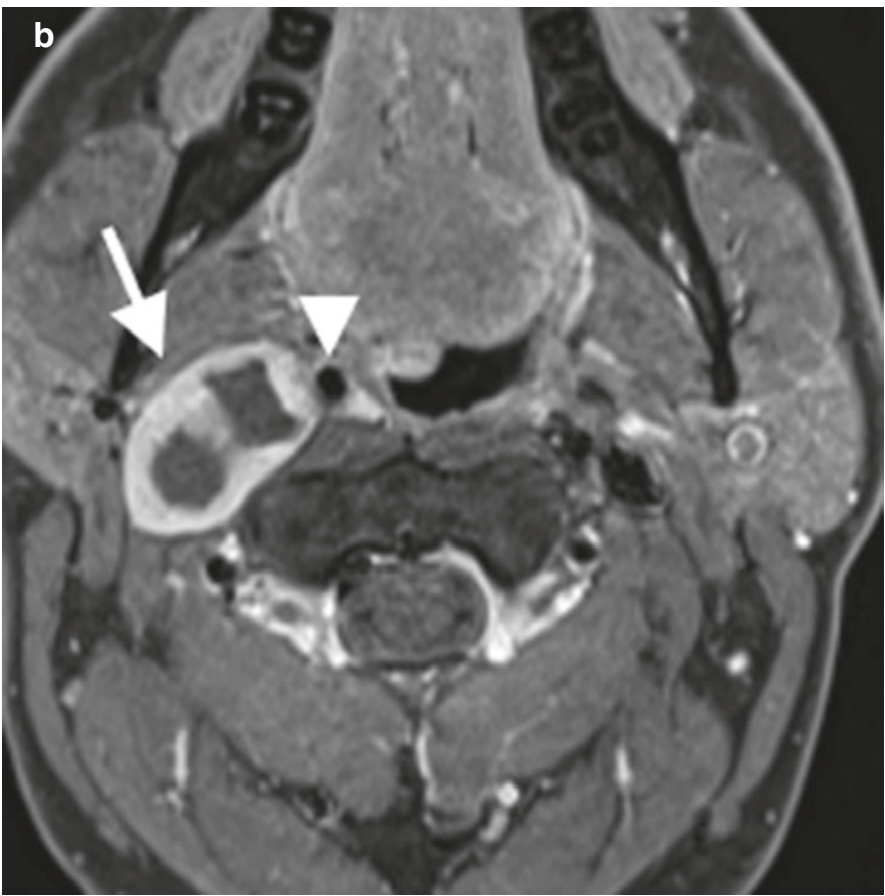

tic change. The ICA flow void is displaced anteromedially (arrowhead) and the IJV is compressed, which further confirms the carotid space origin. Note that retropharyngeal masses will displace the carotid laterally

there is pharyngitis, lymphadenopathy may be reactive and homogenous, or, particularly in children, there may be the development of an intranodal abscess that may rupture into the RPS. RPS lymph nodes may be involved in hematologic malignancy such as lymphoma, or may represent sites of metastatic disease from local malignancies, particularly those of the pharynx, paranasal sinuses, and thyroid gland (Fig. 16.15).

\subsection{Entire Neck: Perivertebral Space}

Anatomy and Contents The perivertebral space (PVS) is a cylindrical space around the vertebral column, invested in the DL-DCF from the skull base to the mediastinum. The PVS can be subdivided into the prevertebral space and the paraspinal space [16]. The contents of the PVS include the vertebral bodies, disc spaces, musculature, and the vertebral arteries in the foramen transversarium. The retropharyngeal space lies directly anterior to the PVS and the paired carotid spaces lie anterolateral. The prevertebral muscles are invested in the anterior DL-DCF, known as the "carpet" by surgeons. It is tenacious and serves as a barrier to infection and neoplasm. Lesions in the PVS tend to lift or displace the prevertebral muscles anteriorly, whereas RPS lesions displace these muscles posteriorly. 
Pathology The vast majority of pathologic lesions in the perivertebral space involve the vertebral bodies and disc spaces, and the minority of lesions are centered in the paraspinal musculature. Therefore, pyogenic discitis/ osteomyelitis and bone metastasis are the most common pathologies found in this space (Fig. 16.16). Atypical infections such as tuberculosis are less common, but have

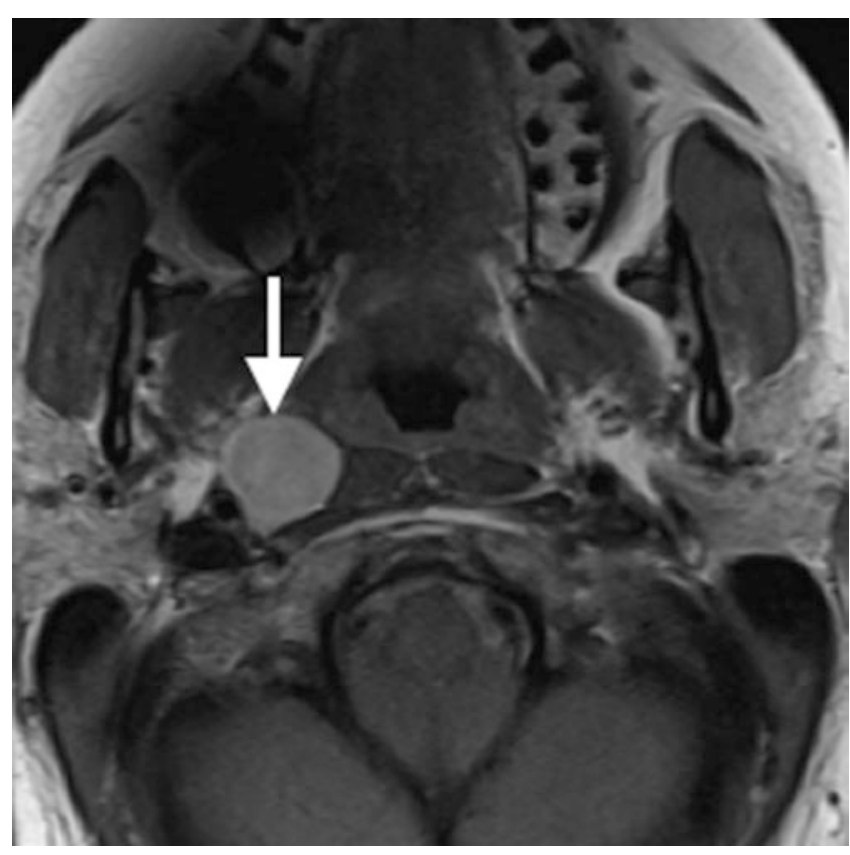

Fig. 16.15 Axial T1-weighted image without contrast shows an enlarged lateral retropharyngeal lymph node in a patient with metastatic papillary thyroid carcinoma. T1 shortening reflects colloid content characteristic imaging features such as sparing of the disc spaces. Primary bone tumors are also uncommon, but have characteristic locations and appearance. For example, chordomas can be suggested when a lesion is found in the upper cervical spine with characteristic bright $\mathrm{T} 2$ signal and enhancement.

\subsection{Concluding Remarks}

The neck is anatomically complex, but can be organized into compartments or "spaces" in order to organize the approach to neck masses. A thorough understanding of fascial planes, the various spaces and their normal contents will help the radiologist generate the best differential diagnoses to appropriately guide management. The parapharyngeal space (PPS) fat is especially important in the analysis of most suprahyoid neck masses, as the mass effect on this triangular fat pad often helps to localize the space of origin. Pathology will displace the PPS in a predictable pattern. For example, masses arising in the deep lobe of the parotid tend to displace the PPS anteromedially, carotid space masses displace the PPS anteriorly, masticator space masses push the PPS posteriorly, and pharyngeal mucosal space masses often push the PPS laterally. Each compartment has common and uncommon pathology, often based on the normal contents. Therefore, once a lesion is localized to the correct space, the radiologist can utilize imaging features and clinical information to provide a tailored list of differential considerations, or in some cases, a specific most likely diagnosis.
Fig. 16.16 (a) Axial CECT shows enlargement and heterogeneous enhancement in the prevertebral space involving the prevertebral muscles and abutting the $\mathrm{T} 2$ vertebral body. (b) Sagittal T1-weighted post gadolinium shows abnormal enhancement of lower cervical and upper thoracic vertebral bodies and a large area of nonenhancement (arrows), compatible with multi-level osteomyelitis. There is also epidural extension of infection (arrowhead)
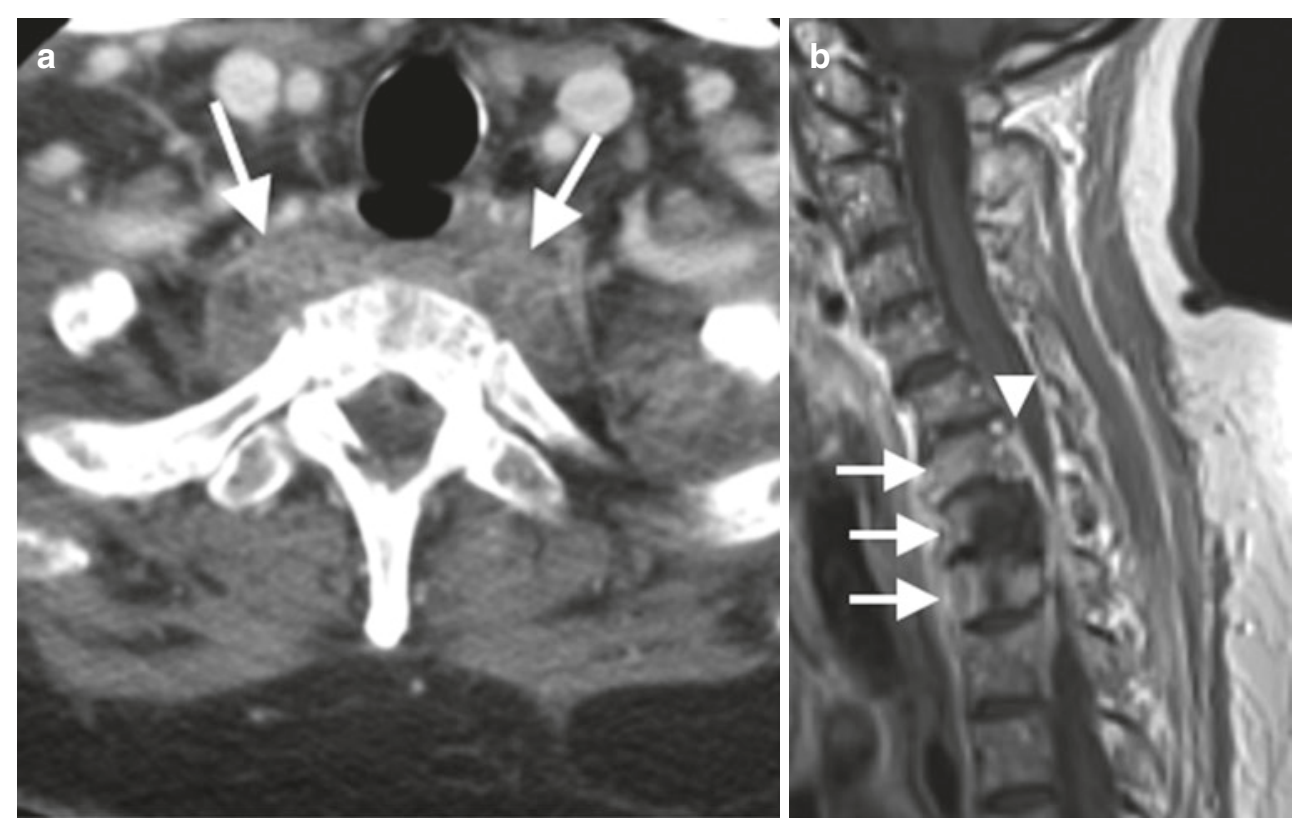


\section{H\&N space contents}

\begin{tabular}{|c|c|c|c|}
\hline Space & Boundaries & Major contents & Common pathology \\
\hline $\begin{array}{l}\text { Pharyngeal } \\
\text { mucosal (PMS) }\end{array}$ & $\begin{array}{l}\text { Mucosa to pharyngeal constrictors } \\
\text { of nasopharynx and oropharynx } \\
\text { (some include hypopharynx and } \\
\text { oral cavity) }\end{array}$ & $\begin{array}{l}\text { Mucosa, Waldeyer's ring, minor } \\
\text { salivary glands, constrictor and levator } \\
\text { palatine muscles, cartilaginous } \\
\text { Eustachian tube }\end{array}$ & $\begin{array}{l}\text { Malignant tumors }(\text { mucosal }=\text { SCC or } \\
\text { NPC and submucosal = minor salivary } \\
\text { tumors or lymphoma) } \\
\text { Pharyngitis, tonsillitis }\end{array}$ \\
\hline $\begin{array}{l}\text { Parapharyngeal } \\
\text { (PPS) }\end{array}$ & $\begin{array}{l}\text { Skull base to mandibular angle, } \\
\text { borders PPS, CS, PS, MS }\end{array}$ & Fat, minor salivary glands & $\begin{array}{l}\text { Benign salivary tumors, rare branchial } \\
\text { cleft cyst or vascular malformation }\end{array}$ \\
\hline Masticator (MS) & $\begin{array}{l}\text { Skull base to mandibular angle, } \\
\text { lateral to PPS }\end{array}$ & $\begin{array}{l}\text { Muscles of mastication, posterior body } \\
\text { and ramus of mandible, CNV3 }\end{array}$ & $\begin{array}{l}\text { Odontogenic infections, venous } \\
\text { malformations, sarcomas }\end{array}$ \\
\hline Parotid (PS) & $\begin{array}{l}\text { Enclosed within the parotid fascia, } \\
\text { lateral to PPS, MS }\end{array}$ & $\begin{array}{l}\text { Parotid gland, } \mathrm{CN} 7, \text { lymph nodes, } \\
\text { retromandibular vein, external carotid } \\
\text { artery branches }\end{array}$ & $\begin{array}{l}\text { Pleomorphic adenoma } \\
\text { Low and high grade malignant salivary } \\
\text { neoplasms } \\
\text { Acute or chronic parotitis }\end{array}$ \\
\hline Visceral (VS) & $\begin{array}{l}\text { Hyoid to mediastinum, anterior to } \\
\text { PVS, medial to CS }\end{array}$ & $\begin{array}{l}\text { Thyroid and parathyroid glands, larynx, } \\
\text { hypopharynx, trachea, esophagus }\end{array}$ & $\begin{array}{l}\text { Thyroid nodules } \\
\text { Thyroid cancer } \\
\text { Parathyroid adenoma } \\
\text { Mucosal SCC } \\
\text { Chondrosarcoma } \\
\text { Diverticula }\end{array}$ \\
\hline Carotid (CS) & $\begin{array}{l}\text { Carotid sheath, enclosed by all } 3 \\
\text { layers of DCF, skull base to aortic } \\
\text { arch (SHN + IFN) }\end{array}$ & $\begin{array}{l}\text { SHN: ICA, IJV, CN 9-12 } \\
\text { IFN: CCA, IJV, CN } 10 \text { (vagus) }\end{array}$ & $\begin{array}{l}\text { Vascular pathology related to carotid } \\
\text { (aneurysm, dissection, arteritis) or jugular } \\
\text { vein (thrombosis or thrombophlebitis) } \\
\text { Nerve sheath tumors } \\
\text { Paragangliomas }\end{array}$ \\
\hline $\begin{array}{l}\text { Retropharyngeal } \\
\text { (RPS) }\end{array}$ & $\begin{array}{l}\text { Skull base to } \mathrm{T} 3 \text {, between visceral } \\
\text { and alar fascia }\end{array}$ & Fat and lymph nodes & $\begin{array}{l}\text { Metastatic lymph nodes (NPC, thyroid, } \\
\text { hypopharynx, lymphoma) } \\
\text { Suppurative lymph nodes (children) } \\
\text { Effusion }\end{array}$ \\
\hline $\begin{array}{l}\text { Perivertebral } \\
\text { (PVS) }\end{array}$ & Skull base to T4, posterior to RPS & $\begin{array}{l}\text { Prevertebral muscles, vertebral bodies, } \\
\text { scalene muscles, brachial plexus roots, } \\
\text { phrenic nerve, vertebral artery and vein }\end{array}$ & $\begin{array}{l}\text { Discitis/osteomyelitis } \\
\text { Longus colli tendinitis } \\
\text { Primary bone tumors (chordoma, ABC, } \\
\text { osteoma, giant cell) } \\
\text { Vertebral metastases } \\
\text { Sarcomas } \\
\text { Nerve sheath tumors }\end{array}$ \\
\hline
\end{tabular}

SCC squamous cell carcinoma, $N P C$ nasopharyngeal carcinoma, $A B C$ aneurysmal bone cyst, $S H N$ suprahyoid neck, $I F H$ infrahyoid neck, $I C A$ internal carotid artery, $C C A$ common carotid artery, $I J V$ internal jugular vein

\section{Take Home Messages}

- The three layers of the deep cervical fascia define spaces, each with unique contents and pathology.

- These spaces can be grouped as suprahyoid or infrahyoid, with some spaces, like the carotid and retropharyngeal spaces, spanning both levels.

- Displacement of the parapharyngeal fat can help determine site of origin of a suprahyoid mass.

- The visceral space is the only space contained entirely in the infrahyoid neck and contains the thyroid and parathyroid glands as well as portions of the aerodigestive tract below the oropharynx.

\section{References}

1. Gamss C, Gupta A, Chazen JL, Phillips CD. Imaging evaluation of the suprahyoid neck. Radiol Clin N Am. 2015;53(1):133-44.

2. Warshafsky D, Goldenberg D, Kanekar SG. Imaging anatomy of deep neck spaces. Otolaryngol Clin N Am. 2012;45(6):1203-21.

3. Guidera AK, Dawes PJ, Fong A, Stringer MD. Head and neck fascia and compartments: no space for spaces. Head Neck. 2014;36(7):1058-68.

4. Parker GD, Harnsberger HR, Jacobs JM. The pharyngeal mucosal space. Semin Ultrasound CT MR. 1990;11(6):460-75.

5. Stambuk HE, Patel SG. Imaging of the parapharyngeal space. Otolaryngol Clin N Am. 2008;41(1):77-10.

6. Meltzer DE, Shatzkes DR. Masticator space: imaging anatomy for diagnosis. Otolaryngol Clin North Am. 2012;45(6):1233-51.

7. Kanekar SG, Mannion K, Zacharia T, Showalter M. Parotid space: anatomic imaging. Otolaryngol Clin North Am. 2012;45(6): $1253-72$. 
8. La'porte SJ, Juttla JK, Lingam RK. Imaging the floor of the mouth and the sublingual space. Radiographics. 2011;31(5):1215-30.

9. Tessler FN, Middleton WD, Grant EG, et al. ACR thyroid imaging, reporting and data system (TI-RADS): white paper of the ACR TI-RADS Committee. J Am Coll Radiol. 2017;14(5): 587-95.

10. Russ G, Bonnema SJ, Erdogan MF, Durante C, Ngu R, Leenhardt L. European thyroid association guidelines for ultrasound malignancy risk stratification of thyroid nodules in adults: the EU-TIRADS. Eur Thyroid J. 2017;6(5):225-37.

11. Loevner LA, Kaplan SL, Cunnane ME, Moonis G. Crosssectional imaging of the thyroid gland. Neuroimaging Clin N Am. 2008;18(3):445-61, vii.
12. Aiken AH. Imaging of thyroid cancer. Semin Ultrasound CT MR. 2012;33(2):138-49.

13. Phillips CD, Shatzkes DR. Imaging of the parathyroid glands. Semin Ultrasound CT MR. 2012;33(2):123-9.

14. Kuwada C, Mannion K, Aulino JM, Kanekar SG. Imaging of the carotid space. Otolaryngol Clin N Am. 2012;45(6):1273-92.

15. Bhatt AA. Non-traumatic causes of fluid in the retropharyngeal space. Emerg Radiol. 2018;25(5):547-51.

16. Mills MK, Shah LM. Imaging of the perivertebral space. Radiol Clin N Am. 2015;53(1):163-80.

Open Access This chapter is licensed under the terms of the Creative Commons Attribution 4.0 International License (http://creativecommons. $\mathrm{org} /$ licenses/by/4.0/), which permits use, sharing, adaptation, distribution and reproduction in any medium or format, as long as you give appropriate credit to the original author(s) and the source, provide a link to the Creative Commons license and indicate if changes were made.

The images or other third party material in this chapter are included in the chapter's Creative Commons license, unless indicated otherwise in a credit line to the material. If material is not included in the chapter's Creative Commons license and your intended use is not permitted by statutory regulation or exceeds the permitted use, you will need to obtain permission directly from the copyright holder. 